\title{
Social comparison, group identity and professional identity. A study with bank clerks
}

\author{
Clelia M. Nascimento.Schulze \\ Universidade Federal de Santa Catalina
}

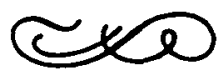

\begin{abstract}
This study consisted of analyzing several bypotheses derived from Taifel and Turner's social identity theory (Taifel and Tumer, 1979) within a real-life situation. We identified the intergroup relations among three banks in Brazil as an ideal chance to test the salience bypothesis (Oakes \& Turner, 1980; Doise E Sinclair, 1973) and also the relationship between discrimination and social identity (Brown et al. 19836). In general, results did not support the bypotheses, and alternative explanations of results, in terms of the groups' real life conditions, are discussed.
\end{abstract}

\section{Comparación social, identidad de grupo y profesional. Un estudio con empleados de banca.}

\section{Resumen}

Este estudio se propuso comprobar varias bipótesis derivadas de la Teoria de la Identidad Social (Tajfel y Turner, 1979) en el marco de una situación de la vida real. Se analizaron las relaciones intergrupales entre tres oficinas bancarias en Brasil, con vistas a validar la hipótesis de saliencia propuesta por autores como Oakes y Tumer (1980) o Doise y Sinclair (1973), y también las bipótesis derivadas de la teoria sabre la relación entre discriminación e identidad social (Brown et al., 1983b). En general, los resultados no confirmaron las predicciones y se consideran explicaciones altemativas relacionadas, fundamentalmente, con las condiciones de vida de los grupos.

Dirección del autor: Rua cap. Romualdo de Barros, 245. BI. C - Apto. 401. Carvoerra. 88040 Florianopolis. Santa Caterina (Brazil)

Original recibido: Mayo 1990 


\section{INTRODUCTION}

The present study is an attempt at observing the conceptual framework proposed by Tajfel and Turner (1979) within a real-life intergroup situation. Their social identity theory inspired two field studies carried out at the University Campus in Florianopolis with bank clerks, academic and non-academic staff members.

In the first study (Nascimento-Schulze, 1987), which served as a background for the second, we looked at the social representations of the bank as an institution, for the social categories used by the community to define the «ideal» bank clerk, and for the clients' and bank clerks' classification of the services banks offer.

Two antagonistic representations of banks emerged, among nine. They were «Bank as a service-offering institution» and «Bank as an exploiting or profitmaking institution».

In the same study, fifteen bank clerks were interviewed ( 5 from each bank). They mentioned as important dimensions for institutional comparison: «social credibility», «seriousness in personnel selection», and «quality of treatment towards the clientele». Efficiency, speed and friendliness emerged as the main characteristics defining the «ideal» bank clerk. Banco do Brasil (BB) and Caixa Econômica Federal (CEF) were classified as generally more efficient and organized than Banco do Estado de Santa Catarina (BESC).

\section{Theoretical Considerations}

Tajfel and Turner (1979) consider the process of social comparison as described by Festinger (1954), together with the categorization process, as central to the formation of social identity. The authors argue that identifications are relational and comparative, so that one defines himself as being «similar to», «different from», «better», or «worse than» outgroup members.

Social comparison, in real life intergroup situations, brings group membership to salience, and the expectations would be that such comparison would lead group members belonging to positively categorised groups to distinguish themselves and their groups from other less positively categorised ones, searching for positive self-esteem and positive social identity.

Oakes and Turner (1980), in an experiment using the «minimal group paradigm», found a significant relation between discrimination and self-esteem. They raised two alternative explanations: either self-esteem increased because Ss discriminated, or because such behaviour made their group membership salient. Thus, the second explanation would be that category salience alone would be sufficient to elevate self-esteem.

Hogg, Turner, Nascimento-Schulze and Spriggs (1986), in two experimental studies, presented evidence that the positive differentiation hypothesis was stronger than the salience hypothesis to explain variations in self-esteem.

Brown et col. (1983a, 1983b), in several field studies, found that the relationship between social identification and differentiation was not consistently positive, but varied between groups. A ten-item inventory for measuring group identification was used in one of the studies (Brown et col. 1983b), based on Driedger's Ethnic Identity Scale (Driedger, 1976).

We identified the intergroup relations among three banks (CEF, BB, and 
BESC), within the University of Santa Catarina's Campus, as ideal to test the salience hypothesis mentioned by Oakes and Turner (1980) and suggested by Doise and Sinclair (1973), and also the relationship between discrimination and social identity discussed by Brown et col. (1983b).

\section{The Research Site}

The Bank of the State of Santa Catarina (BESC), the Bank of Brasil (BB), and the Caixa Economica Federal (CEF) have a branch each on the University Campus. The 4,162 clients and university staff members were encouraged, at the beginning of 1986 , to change banks in which to receive their salaries in case they were not satisfied with the services offered by their current bank. Thus, the possibility to compete for new clients was opened to the three banks. Prior to that, BESC held the privilege of handling all university employees' bank accounts.

BB is a Federal bank, founded three centuries ago. Its bank clerks receive higher salaries compared with the salaries paid by the other two banks. However, their standard of living has constantly been lowered during the last ten years. It offers its employees job security. The admission system is strict and equal for all candidates. It invests in personnel training.

The CEF is also a State Bank. It deals mainly with savings accounts and mortgage systems. It also inspires feelings of security in the general public. It invests in personnel training, having also a strict system of admission.

BESC has the State of Santa Catarina as its main shareholder. It is a recent institution. It does not offer the same job security nor as good salaries as the other two. It does not invest seriously in personnel training. The system of admission does not consider candidates equally.

Prior to the data collection of the first study, a general bank strike took place, led by BB. It was the first strike for 20 years. Fifteen interviews with bank clerks from the three institutions showed their dissatisfaction with their current income. Recently, after the conclusion of the 2nd study, BB and CEF bank clerks have again been involved in strikes for better salaries.

The present study attempted to assess: (1) whether discriminatory responses obtained in a real intergroup relations setting do increase self-esteem, (2) whether group membership salience has an effect on Ss' self-esteem, group identity and professional identity, and (3) whether social comparison and discrimination increase group and professional identity.

In accordance with Social Identity Theory, our expectations were that, after marking comparisons among the three groups, those subjects belonging to the positively categorized groups (BB and $\mathrm{CEF}$ ) would discriminate against the negatively categorized group (BESC). Such discriminations are expected to increase self-esteem and, consequently, group identity. Finally, our expectations were that both social comparison and discrimination would increase the two levels of social identity, i.e., group and professional.

\section{METHOD}

\section{Subjects}

One hundred subjects, bank clerks from the three institutions (BB, BESC and $(E F)$ agreed to take part in the study. 
Fifty bank clerks were from the University Campus Agencies (inside condition), and fifty from agencies outside the University Campus (outside condition).

Fifty-two Ss were assigned to the social comparison condition, and fortyeight to the non-comparison condition.

The Study Design is detailed in Table 1 below.

TABLE 1

Design $(N=100)$

\begin{tabular}{llllllll}
\hline & \multicolumn{3}{c}{ Social Comparison } & \multicolumn{3}{c}{ Non-Comparison } \\
& BESC & CEF & BB & BESC & CEF & BB \\
\hline Inside & $9 \mathrm{Ss}$ & $8 \mathrm{Ss}$ & $9 \mathrm{Ss}$ & $8 \mathrm{Ss}$ & $8 \mathrm{Ss}$ & $8 \mathrm{Ss}$ \\
Outside & $9 \mathrm{Ss}$ & $8 \mathrm{Ss}$ & $9 \mathrm{Ss}$ & $8 \mathrm{Ss}$ & $8 \mathrm{Ss}$ & $8 \mathrm{Ss}$ \\
\hline
\end{tabular}

\section{Dependent Measures}

(a) A Social Comparison Questionnaire was designed, based on the social categories obtained from the first study (Nascimento-Schulze, 1987). The Comparison categories used for membership comparison were: speed, efficiency, friendliness. The comparison categories used for institutional comparison were: credibility, seriousness in personnel selection, and «quality of treatment towards the clientele».

(b) A translated version of Rosenberg's (1965) Self-Esteem Questionnaire was used in its original form.

Responses were summed across 10 items, so that a higher score represents more positive self-esteem.

(c) The twenty-Sentences Test of Kuhn and McPartland (1958) was used. Responses were scored as +1 or -1 , depending on whether they were positively or negatively evaluative, and neutral or irrelevant responses were scored as zero.

(d) A Group Identity Test was developed from Driedger's (1976) Ethnic Identity Test. The questionnaire consisted of 8 questions on group identity which should be firstly answered in terms of «what I presently am» (Real) and 8 identical questions which should be answered in terms of «what I would like to be» (Ideal).

(e) A Professional Identity Test, also developed from Driedger's (1976) instrument, and following the above «real» and «ideal» patterns, was designed.

Responses were, in each scale, summed across 8 items, so that a higher score represents more positive group/professional identity.

\section{Procedure}

The procedure was similar in both Comparison and Non-Comparison conditions.

Ss were approached individually or two by two.

Five questionnaires were given at the same time to the $S$ s in the Comparison condition, and the instructions were read aloud by the experimenter. The Social Comparison Questionnaire was always the first one to be applied.

The Non-Comparison condition followed the same procedure, except that the Social Comparison Questionnaire was omitted. 
The questionnaires were filled in during the working hours inside the banks' agencies.

\section{Results}

From the 52 Ss submitted to the Social Comparison condition (19 BESC, $16 \mathrm{CEF}, 18 \mathrm{BB}), 22 \mathrm{Ss}(11 \mathrm{BB}, 11 \mathrm{CEF})$ discriminated against the negatively categorized group (BESC), as expected. Those numbers correspond to $68 \%$ of CEF Ss and to $61 \%$ of BB Ss.

A pattern of answers was considered as discriminative when the subject classified the ingroup as having a better score than the outgroup in 4 or more categories of comparison.

\section{Self-esteem}

The results are that there were no significant differences in Rosenberg's selfesteem scores. An analysis of variance was made with $\mathrm{Ss}$ ' self-esteem means, and results can be seen in Table 1.

TABLE 1

Means on Rosenberg's self-esteem scale

\begin{tabular}{lrrrrrrr}
\hline & \multicolumn{4}{c}{ Social Comparison } & \multicolumn{3}{c}{ Non-Social Comparison } \\
& & BESC & CEF & BB & BESC & CEF & BB \\
\hline Inside & M & 33,33 & 34,00 & 33,78 & 32,62 & 32,62 & 34,50 \\
Campus & SD & 4,42 & 2,89 & 3,70 & 3,29 & 3,11 & 3,66 \\
\hline Outside & M & 32,78 & 34,25 & 32,89 & 33,25 & 33,87 & 36,25 \\
Campus & SD & 3,46 & 4,30 & 2,52 & 3,62 & 3,79 & 2,12 \\
\hline
\end{tabular}

As it can be seen in Table 2, there were no significant results in a $T$ test between Rosenberg test means of Ss who discriminated and those who did not discriminate.

TABLE 2

《T» test on discriminative $\times$ Non-discriminative group means

\begin{tabular}{ccccccc}
\hline ROS & Ss & Means & SD & d.f. & t value & $P$ \\
\hline Group 1 & 23 & 33,43 & 3,27 & 49 & $-0,07$ & 0,94 \\
Group 2 & 28 & 33,50 & 3,70 & & & \\
\hline
\end{tabular}

A T test on Ss' TST scores revealed that there were no significant differences between the means of the discriminative and the non-discriminative groups (see Table 3). 
TABLE 3

《T》 test on mean TST scores of discriminative and non-discriminative groups

\begin{tabular}{ccccccc}
\hline TST & Ss & Mean & SD & d.f. & t & f \\
\hline Group 1 & 23 & 0,67 & 0,36 & 50 & 0,56 & 0,83 \\
Group 2 & 29 & 0,61 & 0,39 & & & \\
\hline
\end{tabular}

However, an SAS Analysis of variance on Ss' TST scores revealed an unexpectedly significant main effect for CAMPUS ( $\leqslant \leqslant 0,01)$, as can be seen in Table 4 .

TABLE 4

SAS analysis of variance on TST scores

\begin{tabular}{lcccc}
\hline \multicolumn{1}{c}{ Source } & DF & Anova SS & F & P \\
\hline Bank & 2 & 0,4000 & 0,18 & 0,8343 \\
Campus & 1 & 0,9870 & 8,94 & $0,0036^{*}$ \\
Bank $\times$ Campus & 2 & 0,5081 & 2,30 & 0,1063 \\
Comparison & 1 & 0,0110 & 0,10 & 0,7526 \\
Bank $\times$ Comparison & 2 & 0,0423 & 0,19 & 0,8260 \\
Campus × Comparison & 1 & 0,2886 & 2,61 & 0,1096 \\
Bank × Campus Com- & 2 & 0,0836 & 0,38 & 0,6858 \\
parison & 2 & & & \\
\hline
\end{tabular}

$* p \leqslant 0,01$.

In Table 5, we can see the group means. As we can verify, the overall mean pattern shows that, with one exception, group means were higher in the «outside the Campus» condition.

TABLE 5

TST group mean scores

\begin{tabular}{lcccccccc}
\hline & & \multicolumn{3}{c}{ Comparison } & \multicolumn{4}{c}{ Non-Comparison } \\
& & BESC & CEF & BB & BESC & CEF & BB \\
\hline \multirow{3}{*}{ Inside } & $\mathrm{M}$ & 0,52 & 0,52 & 0,41 & 0,78 & 0,53 & 0,52 & \\
& SD & 0,46 & 0,18 & 0,51 & 0,41 & 0,29 & 0,19 & 0,54 \\
& $\mathrm{M}$ & 0,73 & 0,73 & 0,88 & 0,62 & 0,68 & 0,80 & \\
Outside & $\mathrm{SD}$ & 0,30 & 0,25 & 0,23 & 0,31 & 0,35 & 0,20 & 0,74 \\
\hline
\end{tabular}

An examination of frequencies of TST answers of the type 1 (negative statements about self) shows that, particularly during the «Comparison X Inside the Campus» condition - where the social comparison is more realistic and salient-Ss of the 3 groups presented higher frequencies of negative evaluations about the Self (See Table 6). 
TABLE 6

Global frequencies for type 1 answers on TST

\begin{tabular}{lcccccc}
\hline & & Comparison & \multicolumn{3}{c}{ Non-Comparison } \\
& BESC & CEF & BB & BESC & CEF & BB \\
\hline Inside & 40 & 31 & 31 & 6 & 25 & 21 \\
Outside & 17 & 16 & 4 & 17 & 15 & 11 \\
\hline
\end{tabular}

An as above the frequencies of type 2 answers shows us that there was no outstanding increase of type 2 answers (positive statements about Self) for the «outside the Campus» condition (see Table 7). These results allow us to conclude that it was the increase of Type 1 answers -especially in the high salience condition - which accounted for the significant main effect for Campus.

TABLE 7

Global frequencies for type 2 answers in TST

\begin{tabular}{lcccccc}
\hline & \multicolumn{3}{c}{ Comparison } & \multicolumn{3}{c}{ Non-Comparison } \\
& BESC & CEF & BB & BESC & CEF & BB \\
\hline Inside & 85 & 98 & 64 & 71 & 90 & 66 \\
Outside & 102 & 87 & 72 & 87 & 85 & 72 \\
\hline
\end{tabular}

A $T$ Test between the means of the discriminative $X$ non-discriminative group was calculated for the 4 different measurements of social identity (RPI, IPI, RGI, IGI). Results revealed a significant difference in RGI (see Table 8).

TABLE 8

T Test on IPI, RPI, IGI, RGI means of discriminative and non-discriminative groups

\begin{tabular}{llccccc}
\hline & Variable & $\begin{array}{c}\text { Number } \\
\text { Cases }\end{array}$ & Mean & SD & t & p \\
\hline IPI & Group 1 & 23 & 32,34 & 4,42 & 0,30 & 0,76 \\
& Group 2 & 29 & 31,96 & 4,60 & & \\
\multirow{2}{*}{ RPI } & Group 1 & 23 & 30,30 & 2,97 & 0,33 & 0,74 \\
& Group 2 & 29 & 29,96 & 4,42 & & \\
IGI & Group 1 & 23 & 33,30 & 3,71 & 0,95 & 0,34 \\
& Group 2 & 29 & 32,27 & 4,05 & & \\
RGI & Group 1 & 23 & 31,00 & 2,68 & 1,60 & $0,10^{*}$ \\
& Group 2 & 29 & 29,00 & 5,51 & & \\
\hline
\end{tabular}

$* p \leqslant 0,01$

Such results confirm the expectation that discrimination would increase group identity. 
Although means differed significantly only for RGI, results in Table 8 show that the discriminative group systematically presented a slightly higher mean score than the non-discriminative group.

An analysis of variance was made with Ss' professional and group identity scores (Real and Ideal). Results were as follows:

\section{Group Identity}

RGI

The analysis of variance in RGI revealed one main effect for CAMPUS $(p \leqslant 0,001)$. Ss inside the Campus presented a mean significantly lower than $\mathrm{Ss}$ outside the Campus (inside $=29,75$; outside $=32,50$ ). It also revealed a main effect for Social Comparison $(p \leqslant 0,005)$. Thus, Ss who answered the Social Comparison Questionnaire produced significantly lower means than $\mathrm{Ss}$ who did not answer it.

Also, a two-way interaction Bank X Comparison was found ( $p \leqslant 0,01)$, in which BESC and BB had lower RGI scores in the social comparison condition than in the non-comparison. Here, only the negatively categorized group results were in agreement with the expectations.

Table 9 displays the overall means in Real Group Identity.

TABLE 9

RGI means and S.D.

\begin{tabular}{rrrrrrrr}
\hline & \multicolumn{3}{c}{ Comparison } & \multicolumn{3}{c}{ Non-Comparison } \\
& & BESC & CEF & BB & BESC & CEF & BB \\
\hline Inside the & M & 25,00 & 31,12 & 29,89 & 31,62 & 29,25 & 31,62 \\
Campus & SD & 4,07 & 3,28 & 3,89 & 4,71 & 3,46 & 3,89 \\
& M & 32,11 & 32,50 & 29,67 & 33,25 & 33,25 & 34,25 \\
Outside & SD & 4,80 & 2,08 & 4,78 & 3,61 & 3,06 & 2,77 \\
\hline
\end{tabular}

\section{IGI}

A significant main effect was found for the variable comparison $(p \leqslant 0,01)$. Ss who did not answer the social comparison questionnaire presented higher IGI than Ss who answered it.

In Table 10 we can observe that, although not significantly different, IGI was higher outside than inside the Campus.

TABLE 10

IGI means and S.D.

\begin{tabular}{rrrrrrrr}
\hline & & \multicolumn{3}{c}{ Comparison } & \multicolumn{3}{c}{ Non-Comparison } \\
& & BESC & CEF & BB & BESC & CEF & BB \\
\hline Inside the & M & 30,78 & 32,75 & 32,67 & 33,12 & 34,88 & 33,12 \\
Campus & SD & 2,99 & 3,58 & 3,88 & 2,64 & 3,13 & 3,57 \\
& & & & & & & \\
Outside & M & 32,67 & 35,38 & 32,44 & 34,62 & 34,00 & 35,38 \\
& SD & 3,50 & 2,67 & 5,66 & 3,70 & 5,50 & 2,00 \\
\hline
\end{tabular}




\section{Professional Identity}

\section{RPI}

A main effect for CAMPUS was found in «Real Professional Identity» scores $(p \leqslant 0,05)$. Ss inside the Campus presented a lower score in RPI than Ss outside the Campus (inside $=29,30$ - outside $=31,87$ ). See Table 11 for means.

TABLE 11

RPI means and S.D.

\begin{tabular}{lrrrrrrr}
\hline & & \multicolumn{3}{c}{ Comparison } & \multicolumn{3}{c}{ Non-Comparison } \\
& & BESC & CEF & BB & BESC & CEF & BB \\
\hline \multirow{2}{*}{ Inside } & M & 26,89 & 30,88 & 28,56 & 30,88 & 30,25 & 29,25 \\
& SD & 3,44 & 3,19 & 3,39 & 3,64 & 3,70 & 3,38 \\
\multirow{2}{*}{ Outside } & $\mathrm{M}$ & 31,78 & 32,38 & 30,56 & 32,50 & 31,12 & 32,88 \\
& $\mathrm{SD}$ & 3,52 & 1,60 & 4,74 & 5,21 & 4,59 & 4,46 \\
\hline
\end{tabular}

As we can observe in Table $11, \mathrm{BESC}$ and BB means were distinctly different with regard to the Inside Campus $\mathrm{X}$ Outside Campus condition.

\section{IPI}

A main effect for bank emerged in IPI scores analysis ( $p \leqslant 0,01)$. CEF presented higher IPI scores than the two other banks:

Before closing the results section, two points have to be stressed. An examination of Real and Ideal means shows that -although not statistically significant - there was a difference from the Ideal to the Real pattern, in such a way that the means of the Ideal Identity Questionnaires were distinctly higher in all conditions. They were particularly higher within the Campus condition, and BESC always displayed the most distinct means.

As far as the internal reliability of the 4 instruments here considered is concerned, the RGI questionnaire presented a reasonable internal reliability with Cronbach's $\alpha=0,70$. The other 3 questionnaires revealed an $\alpha$ near 0,60 and a close examination of the scales variance related to each item suggests the reformulation of some of the items.

\section{DISCUSSION}

The expectation that discriminatory responses would increase self-esteem was not fulfilled. Subjects of the positively categorized groups indeed discriminated against the negatively categorized ones, but there was no increase in Ss' self-esteem subsequent to the discrimination.

The expectation that discrimination would increase group and professional identity of the positively categorized groups was only satisfied in the case of RGI, where Ss who did discriminate presented higher scores than the Ss who did not.

As far as social comparison is concerned, it had an effect on RGI, but not in the expected direction. Unexpectedly, Ss of the 3 groups under the social 
comparison condition presented lower levels of RGI than Ss under the noncomparison condition. Lower results actually obtained for group identity were only expected in the case of the negatively categorized groups, and not of the other two.

An expectation compatible with the theory would be that the social comparison questionnaire would make ingroup - outgroup membership more salient for the Ss under this condition, and that this increased salience of the social categorization would raise the self esteem of the positively categorized group members. Results show just the opposite pattern.

Similarly, the variable "inside X outside the Campus" acted in an unexpected way upon RGI, bringing lower levels of group identity. The "inside the Campus" condition could be interpreted as a more salient situation than the "outside the Campus" condition, since it stresses group membership and makes competition more explicit.

In both cases, unexpectedly, salient group membership seems to be working as a depressing force on self-esteem and group identity, leading to lower rather than higher scores.

It seems to us that alternative explanations for the unexpected results have to be searched for within the groups' real-life conditions.

As regards the results related to BESC, the group was negatively categorized in a previous study, and suffered great discrimination from $\mathrm{BB}$ and $\mathrm{CEF}$ members in the present study. In the "inside the Campus" X "social comparison conditions", BESC's members presented the highest frequency of negative self-categorization in the TST, and the lowest levels of real professional identity and group identity compared to the other two banks. All the present results were in agreement with the expectations. In fact, such results are a mirror of what outgroup members and university community members answered in questionnaires with regard to BESC in a previous study. However, results were somewhat puzzling, particularly when we observe $\mathrm{BB}$ scores in social identity and self-esteem post-discrimination. The intergroup setting to be described below suggested positive distinction, higher self-esteem and higher levels of social identity for $\mathrm{BB}$ and $\mathrm{CEF}$ members.

The University Campus setting differs qualitatively from the city setting, in so far as the 3 banks are the only ones in the Campus. BB and BESC agencies are placed very close to each other in spacial terms - a fact which makes the group membership and comparison still more salient.

Many of the clients keep accounts in two or even in three banks, social comparisons being openly made during daily interactions.

In the city setting, bank clerks of the 3 banks are faced with 15 other private banks to compete and compare themselves with. Thus, the group membership and comparison categories, salience is more diffused. Also, the social interaction is more formal and more scarce than the interaction existent in the Campus setting.

Perhaps these setting characteristics may account for the magnitude of the results obtained with regard to the "inside X outside the Campus" variable.

However, an explanation of the fact that "setting" and "social comparison" produced effects contrary to the theory's expectations may be found after we analyse the major differences between the "minimal groups" and the "real life groups". Minimal groups are qualitatively different from real life groups in so far as (i) their members do not share a common history, (ii) there are no pre- 
vious and socially shared attributions made towards them, and (iii) there is no scope for their members to establish intergroup relations within a dimension of perceptions of social stratification which is also shared by members of the other relevant groups.

Conversely, in the present bank intergroup relations setting, members of the three groups do share a common history, they are aware of the social attributions and categorizations imputed to each group and, consequently, they do classify themselves and their institutions on the basis of real linguistic categories, which give shape to their professional and group identities and are broadly shared by members of the relevant outgroups.

The basic differences mentioned above, and the particularities of each intergroup setting, may lead to different associations among variables such as social comparison, ingroup favouritism, social competition, self-esteem and social identity. Thus, the positive relation between ingroup favouritism, social competition and an increase in self-esteem may not necessarily occur in real intergroup relations.

Following this line of argument, the discrimination presented by members of $\mathrm{BB}$ and $\mathrm{CEF}$ towards $\mathrm{BESC}$ might not represent a strategy of social competition moved by a desire for social distinctiveness and a desire for enhancing self-esteem, but by a choice of reporting social categorizations, shared by the community, and attributed to the three distinct groups. Perhaps the positive group distinctiveness obtained from the social comparisons gave rise to a feeling of discomfort rather than a feeling of self-enhancing, and consequently Ss' self-esteem was lower than during other conditions where comparison was less salient.

We are trying to argue that the discrimination presented by Ss of the minimal group experiments is different from the discrimination presented here.

One last explanation of the unexpected results could be that the previous history of the groups interacted with the experimenter's manipulations. An example based on real-life facts is that members of BB used to have one of the best salaries among all categories of civil servants, whereas nowadays their salaries are no longer comparatively outstanding. Interviews with BB bank clerks made in a former study revealed a certain discredit and disappointment with the profession, and perhaps even with the group membership. Thus, in a setting where their group affiliation is more salient, BB Ss may also be clearer about their economic loss and, consequently, present lower levels of self-esteem.

The present study suggests that other experiments be run in real-life settings, with larger numbers of $S s$, and examining specifically the relationship between intergroup salience, social comparison and self-esteem.

\section{References}

BRown, R. J. \& Williams, J. A. (1983)a. Group identification: the same thing to all people? Unpublished manuscript. University of Kent.

Brown, R. J.; Wade, W.; Mathews, A.; Conder, S. \& W Wlluams, J. (1983b). Group identification and intergroup differentiation. Paper presented at the annual conference of the British Psychological Society (Social Psychology Section), Sheffield.

DoISE, W. \& SinClAIR, A. (1973). "The categorization process in intergroup relations"; European Joumal of Social Psychology, 3: 145-157.

DRIEDGER, L. (1976). Ethnic self-identity: a comparison of ingroup evaluations. Sociometry, 39, 131-141. 
Hogg, M.; Turner, J. C.; Nascimento-Schulze, C. M. \& Spriggs, D. (1986). Social categorization, intergroup behaviour and self-esteem: Two experiments. Revista de Psicología Social, 1, 23-38.

Kuhn, M. H. \& McPartLand, T. S. (1954). "An empirical investigation of self-attitudes", American Sociological Review, 19: 68-76.

Nascimento-Schulze, C. M. (1987). Social Identity and Social Representation, a study with bank clerks. Unpublished manuscript presented at the 3rd International Conference of Social Psychology and Language, Bristol, July.

OAKES, P. J. \& TURNER, J. C. (1980). Social categorization and intergroup behaviour: does minimal intergroup discrimination make social identity more positive? European Joumal of Social Psychology, 10, 295-301.

Rosenberg, M. (1965). Society and Adolescent Self-image. PRINCETON, N. J.: Princeton University Press.

TAJFel, H. \& TURNER, J. C. An integrative theory of intergroup conflict (1979). In W. G Austin and Werchel (Orgs). The Social Psychology of Intergroup Relations. Monterey, California: Brooks-Cole.

Questions below refer to comparison between bank clerks at different institutions (BESC, BB and $(E F$ ). Please qualify them, marking one among the five adjectives listed (very poor, poor, fair, good, exceptional). Mark with an X the most likely answer. Please mark all six questions.

(1) COMPARE BANK CLERKS BELOW REGARDING SPEED IN TASK PERFORMANCE.
(A) $\mathrm{BB}$
( ) VERY POOR ( ) POOR ( ) FAIR
( ) GOOD
( ) EXCEPTIONAL
(B) BESC
() VERY POOR ( ) POOR ( ) FAIR
( ) GOOD
( ) EXCEPTIONAL
() VERY POOR ( ) POOR ( ) FAIR
( ) GOOD
( ) EXCEPTIONAL

(2) COMPARE BANK CLERKS BELOW ACCORDING TO THEIR EFFICIENCY.
(A) $\mathrm{BB}$
( ) VERY POOR（） POOR （） FAIR
( ) GOOD
( ) EXCEPTIONAL
(B) BESC
() VERY POOR（） POOR （） FAIR
( ) GOOD
( ) EXCEPTIONAL
(C) CEF
() VERY POOR ( ) POOR （） FAIR
( ) GOOD
( ) EXCEPTIONAL

(3) COMPARE BANK CLERKS BELOW REGARDING CLIENT HANDLING, THAT IS, FRIENDLINESS
(A) $\mathrm{BB}$
(A) VERY POOR ( ) POOR ( ) FAIR
( ) GOOD
( ) EXCEPTIONAL
(B) BESC
() VERY POOR ( ) POOR ( ) FAIR
( ) GOOD
( ) EXCEPTIONAL
(C) $\mathrm{CEF}$
( ) GOOD
( ) EXCEPTIONAL

(4) COMPARE THE 3 INSTITUTIONS BELOW REGARDING CREDIBILITY ATTRIBUTED TO EACH BY THE POPULATION.
(A) $\mathrm{BB}$
( ) VERY POOR ( ) POOR （ ) FAIR
( ) GOOD
( ) EXCEPTIONAL
(B) BESC
( ) GOOD ( ) EXCEPTIONAL
(C) CEF
(c) VERY POOR ( ) POOR ( ) FAIR
( ) GOOD
( ) EXCEPTIONAL

(5) COMPARE THE 3 INSTITUTIONS BELOW REGARDING THEIR ENDEAVOUR AS
TO SERIOUSNESS IN PERSONNEL SELECTION.

(A) $\mathrm{BB}$

( ) VERY POOR ( ) POOR ( ) FAIR

( ) GOOD

( ) EXCEPTIONAL

(B) BESC

( ) VERY POOR ( ) POOR ( ) FAIR

( ) GOOD

( ) EXCEPTIONAL

(C) $\mathrm{CEF}$

() VERY POOR ( ) POOR ( ) FAIR

( ) GOOD

( ) EXCEPTIONAL

(6) COMPARE THE 3 INSTITUTIONS BELOW REGARDING THE QUALITY OF SERVICES OFFERED TO THE GENERAL PUBLIC.
(A) $\mathrm{BB}$
() VERY POOR ( ) POOR ( ) FAIR
( ) GOOD
( ) EXCEPTIONAL
(B) $\mathrm{BESC}$
( ) VERY POOR ( ) POOR ( ) FAIR
( ) GOOD
( ) EXCEPTIONAL
(C) CEF
() VERY POOR ( ) POOR ( ) FAIR
( ) GOOD
( ) EXCEPTIONAL 
This questionnaire regards the way you feel about your profession. You will have the same questions presented twice: the first time, your answer must convey the way you would like to feel. The second time, you must answer the questions having in mind what you really feel or are. Please answer the questions as fast as possible, and do your best to be sincere.

(1) I WOULD LIKE TO BE A PERSON WHO:

\section{( ) NEVER \\ ( ) SELDOM \\ () SOMETIMES \\ ( ) OFTEN \\ ( ) VERY OFTEN}

1. REGARDS BANK CLERKS' SOCIAL CONTRIBUTION AS IMPORTANT

2. IS INCLINED TO HIDE FROM OTHER PEOPLE THE FACT THAT HE IS A BANK CLERK

( ) NEVER

( ) SELDOM

( ) SOMETIMES

( ) OFTEN

( ) VERY OFTEN

3. IS PROUD TO BELONG TO THE PROFESSIONAL GROUP OF BANK CLERKS

( ) NEVER

( ) SELDOM

( ) SOMETIMES

() OFTEN

( ) VERY OFTEN

4. SUFFERS FROM A SENSE OF INFERIORITY WHEN FACING INDIVIDUALS FROM OTHER PROFESSIONAL CATEGORIES

( ) NEVER

( ) SELDOM

(i) SOMETIMES

( ) OFTEN

( ) VERY OFTEN

5. DERIVES PLEASURE FROM REMEMBERING HIS PROFESSIONAL PAST

( ) NEVER

( ) SELDOM

( ) SOMETIMES

( ) OFTEN

( ) VERY OFTEN

6. CRITICIZES THE ROLE PLAYED BY BANK CLERKS

( ) NEVER

( ) SELDOM

( ) SOMETIMES

( ) OFTEN

( ) VERY OFTEN

7. CONTRIBUTES TO CLASS DEBATES, DISCUSSIONS, AND ASSEMBLIES

( ) NEVER

( ) SELDOM

( ) SOMETIMES

( ) OFTEN

( ) VERY OFTEN

8. FEELS ASHAMED TO BELONG TO THE PROFESSIONAL CLASS OF BANK CLERKS

( ) NEVER

( ) SELDOM

( ) SOMETIMES

( ) OFTEN

( ) VERY OFTEN
(1) I AM A PERSON WHO:

1. REGARDS BANK CLERKS' SOCIAL CONTRIBUTION AS IMPORTANT

( ) NEVER

() SELDOM

( ) SOMETIMES

() OFTEN

( ) VERY OFTEN

2. IS INCLINED TO HIDE FROM OTHER PEOPLE SAME

( ) NEVER

() SELDOM

( ) SOMETIMES

( ) OFTEN

( ) VERY OFTEN

3. IS PROUD TO BELONG TO THE PROFESSIONAL GROUP OF BANK CLERKS

( ) NEVER

() SELDOM

( ) SOMETIMES

( ) OFTEN

( ) VERY OFTEN

4. SUFFERS FROM A SENSE OF INFERIORITY WHEN FACING INDIVIDUALS FROM OTHER PROFESSIONAL CATEGORIES

( ) NEVER

( ) SELDOM

( ) SOMETIMES

( ) OFTEN

( ) VERY OFTEN

DERIVES PLEASURE FROM REMEMBERING HIS PROFESSIONAL PAST

( ) NEVER

() SELDOM

() SOMETIMES

() OFTEN

() VERY OFTEN

6. CRITICIZES THE ROLE PLAYED BY BANK CLERKS

( ) NEVER

() SELDOM

( ) SOMETIMES

() OFTEN

( ) VERY OFTEN

7. CONTRIBUTES TO CLASS DEBATES, DISCUSSIONS, AND ASSEMBLIES

( ) NEVER

( ) SELDOM

( ) SOMETIMES

() OFTEN

( ) VERY OFTEN

8. FEELS ASHAMED TO BELONG TO THE PROFESSIONAL CLASS OF BANK CLERKS

( ) NEVER

( ) SELDOM

( ) SOMETIMES

( ) OFTEN

( ) VERY OFTEN 
This questionnaire is similar to the one you have just answered. Again, you must answer the questions both reflecting the way you actually are or feel and the way you would like to be or feel. Mark one answer only for each question, answering as fast and sincerely as you can.

(1) I WOULD LIKE TO BE A PERSON WHO:

1. REGARDS THE SOCIAL CONTRIBUTION MADE BY BANK CLERKS OF THE

\begin{tabular}{ll}
$(1)$ & \multicolumn{1}{c}{ NEVER AS VE } \\
() & SELDOM \\
() SOMETIMES \\
() OFTEN \\
VERY OFTEN
\end{tabular}

2. FEELS INCLINED TO HIDE THE FACT OF BEING A BANK CLERK WITH
( ) NEVER
( ) SELDOM
( ) SOMETIMES
( ) OFTEN
( ) VERY OFTEN

3. IS PROUD TO BELONG TO THE GROUP OF BANK CLERKS WITH
( ) NEVER
( ) SELDOM
( ) SOMETIMES
( ) OFTEN
( ) VERY OFTEN

4. SUFFERS FROM A SENSE OF INFERIORITY WHEN FACING INDIVIDUALS WHO BELONG TO SOME OTHER GROUP OF BANK CLERKS.
( ) NEVER
( ) SELDOM
( ) SOMETIMES
( ) OFTEN
( ) VERY OFTEN

5. DERIVES PLEASURE FROM REMEMBERING HIS/HER PAST PROFESSIONAL WORK AS A BANK CLERK WITH

\section{( ) NEVER \\ ( ) SELDOM \\ ( ) SOMETIMES \\ ( ) OFTEN \\ ( ) VERY OFTEN}

6. CRITICIZES THE WAY TASKS ARE PERFOR. MED BY BANK CLERKS OF
( ) NEVER
( ) SELDOM
( ) SOMETIMES
( ) OFTEN
( ) VERY OFTEN

7. CONTRIBUTES TO DEBATES AND DISCU. SSIONS SEEKING TO PROMOTE WELL BEING AMONG EMPLOYEES OF
( ) NEVER
( ) SELDOM
( ) SOMETIMES
( ) OFTEN
( ) VERY OFTEN

8. FEELS ASHAMED TO BELONG TO THE PROFESSIONAL GROUP OF BANK CLERKS WITH
( ) NEVER
( ) SELDOM
( ) SOMETIMES
( ) OFTEN
( ) VERY OFTEN

(1) I AM A PERSON WHO:

1. REGARDS THE SOCIAL CONTRIBUTION GIVEN BY BANK CLERKS OF THE
( ) NEVER
( ) SELDOM
( ) SOMETIMES
( ) OFTEN
( ) VERY OFTEN

2. FEELS INCLINED TO HIDE THE FACT OF BEING A BANK CLERK WITH
( ) NEVER
( ) SELDOM
( ) SOMETIMES
( ) OFTEN
( ) VERY OFTEN

3. IS PROUD TO BELONG TO THE GROUP OF BANK CLERKS WITH
( ) NEVER
( ) SELDOM
( ) SOMETIMES
( ) OFTEN
( ) VERY OFTEN

4. SUFFERS FROM A SENSE OF INFERIORITY WHEN FACING INDIVIDUALS WHO BELONG TO SOME OTHER GROUP OF BANK CLERKS.
( ) NEVER
( ) SELDOM
( ) SOMETIMES
( ) OFTEN
( ) VERY OFTEN

5. DERIVES PLEASURE FROM REMEMBERING HIS/HER PAST PROFESSIONAL WORK AS A BANK CLERK WITH
( ) NEVER
( ) SELDOM
( ) SOMETIMES
( ) OFTEN
( ) VERY OFTEN

6. CRITICIZES THE WAY TASKS ARE PERFORMED BY BANK CLERKS OF

( ) NEVER

( ) SELDOM

( ) SOMETIMES

( ) OFTEN

( ) VERY OFTEN

7. CONTRIBUTES TO DEBATES AND DISCU. SSIONS SEEKING TO PROMOTE WELLBEING AMONG EMPLOYEES OF
( ) NEVER
( ) SELDOM
( ) SOMETIMES
( ) OFTEN
( ) VERY OFTEN

8. FEELS ASHAMED TO BELONG TO THE PROFESSIONAL GROUP OF BANK CLERKS WITH
() NEVER
( ) SELDOM
( ) SOMETIMES
( ) OFTEN
( ) VERY OFTEN 